\section{Antioxidant properties of topical Caulerpa sp. extract on UVB-induced photoaging in mice}

\author{
Anak Agung Gde Putra Wiraguna, ${ }^{1}$ \\ Wimpie Pangkahila, ${ }^{2}$ \\ I. Nyoman Mantik Astawa ${ }^{3}$ \\ ${ }^{1}$ Dermatology Department, Faculty of \\ Medicine; ${ }^{2}$ Anti-Aging Medicine \\ Department, Faculty of Medicine; \\ ${ }^{3}$ Virology Laboratory, Faculty of \\ Veterinary Medicine, Udayana \\ University, Indonesia
}

\begin{abstract}
Caulerpa sp., a genus of seaweed native to the Indo-Pacific region, has been known for its antioxidant properties and health benefits when consumed as food. Previous studies have reported Caulerpa sp.'s potential as a strong antioxidant, but its effects on the skin in a topical preparation, especially its role in ultraviolet (UV) protection, have not been studied extensively. Our study investigated the protective effects of $0.2 \%$ and $0.4 \%$ Caulerpa sp. extract gels on photoaging in the UVB-irradiated skin of Wistar mice. The subjects were divided into naive control, vehicle control, and 3 treatment groups $(0.2 \%$ Caulerpa $s p$. extract gel, $0.4 \%$ Caulerpa $s p$. extract gel, and $0.02 \%$ astaxanthin gel as a standard antioxidant). The groups, except the naive control group, received a total of $840 \mathrm{~mJ} / \mathrm{cm}^{2}$ of UVB irradiation in four weeks. Protective effects of the extract were measured through the evaluation of collagen expression, matrix metalloproteinase (MMP)-1 expression and levels, and 8-OhDG expression. Mice who received topical application of Caulerpa $s p$. extract gel had higher collagen expression, better-preserved collagen structure, lower levels of MMP-1, and less MMP-1 and 8OHdG expressions compared to the vehicle control group. There was no difference between different concentrations of the extract. Our findings demonstrated that topical application of Caulerpa sp. extract gel significantly protected UVB-irradiated mice skin from photoaging.
\end{abstract}

\section{Introduction}

Ultraviolet (UV) radiation is an important external factor in skin aging due to its effects on the skin's structures and functions, ${ }^{1}$ especially UV-B (290-320 nm), which delivers more energy than UVA. Due to its shorter wavelength, UVB is mostly absorbed in the epidermis, but is able to reach the papillary dermis. ${ }^{2}$ Photoaging results in the degradation of collagen, elastin, and other components of the extracellular matrix (ECM), causing pigmentation, wrinkles, changes in skin texture, and histologic changes. ${ }^{3}$ UV exposure to the skin produces free radicals in the form of reactive oxygen species (ROS). ROS is known to damage DNA through oxidation of $\mathrm{C} 8$ guanine base, creating 8-hydroxy-2deoxyguanosine $(8-\mathrm{OHdG})$, which is a biomarker of oxidative DNA damage. ${ }^{4}$

Furthermore, free radicals will activate cytokine receptors and growth factors in keratinocytes and fibroblasts, which will activate nucleus transcription factors of activator protein-1 (AP-1) through the induction of mitogen-activated protein kinase (MAP kinase)..$^{5}$ AP-1 will induce the expression of matrix metalloproteinases (MMPs), which are a group of matrixdegrading enzymes. MMP-1 will degrade type I, II, and, III collagen in the skin. ${ }^{3}$

Photoaging is a prevalent problem, especially in tropical countries with yearlong sunshine. Traditional sunscreens do not fully protect the skin from the formation of free radicals. Thus, the addition of antioxidant agents in sunscreens is expected to strengthen the protective effects of sunscreens against UV rays. ${ }^{6}$

Caulerpa sp. is a genus of algae native to the Indo-Pacific region. Locally known as bulung boni, its succulent texture makes it a commonly found delicacy in the islands of Indonesia. Caulerpa $s p$. is found to contain many types of antioxidants and vitamins, such as astaxanthin, beta carotene, vitamin $\mathrm{C}$, vitamin $\mathrm{E}$, and polyphenols. ${ }^{7}$

In this study, we aim to investigate the protective effects of topical Caulerpa $s p$. extract against ultraviolet-induced aging of the skin through the evaluation of collagen in the dermis, 8-OHdG expression, MMP-1 expression, and MMP-1 levels in mice.

\section{Materials and Methods}

\section{Materials}

Caulerpa sp. from Bali, Indonesia, was extracted using ethanol and concentrated using a Danke and Kunkel rotary vacuum evaporator in the Agriculture Technology Laboratory, Udayana University. The extract was made into $0.2 \%$ and $0.4 \%$ gels by ROI Surya Prima Farma in Surabaya, Indonesia. The comparison gel, containing astaxanthin obtained from Fuji Chemical Industry Co Ltd, was produced by
Correspondence: Anak Agung Gde Putra Wiraguna, Dermatology Department, Faculty of Medicine, Udayana University, Indonesia. E-mail: wiraguna@unud.ac.id

Key words: Caulerpa sp., photoaging, antioxidant, UVB radiation.

Conflict of interest: the authors declare no potential conflict of interest.

Received for publication: 21 January 2018. Revision received: 18 July 2018.

Accepted for publication: 19 July 2018.

This work is licensed under a Creative Commons Attribution NonCommercial 4.0 License (CC BY-NC 4.0).

(C) Copyright A.A.G.P. Wiraguna et al., 2018 Licensee PAGEPress, Italy

Dermatology Reports 2018; 10:7597

doi:10.4081/dr.2018.7597

ROISurya Prima Farma.

Standard kits of MMP-1 antibody, 8OHdG antibody, formaldehyde, $\mathrm{NaH}_{2} \mathrm{PO}_{4}$, paraffin, xylol, Sirius red, ethanol, Avidin$\mathrm{HRV}$, and DAB were used in the analysis of samples.

\section{Animals}

Thirty male Wistar (Rattus norvegicus) mice (age 10-12 weeks) weighing 200-250 grams were obtained from the Udayana University Animal Laboratory. The mice were divided into five groups of six mice, including one control group. The naive control (NC) group did not receive any treatment, the vehicle control group (VC) received a type of gel without any active ingredients, Group 1 received $0.02 \%$ astaxanthin gel as standard antioxidant, Group 2 received $0.2 \%$ Caulerpa $s p$. extract gel, and Group 3 received 0.4 Caulerpa sp. extract gel. The VC group and Group 1-3 received $0.05 \mathrm{mg} / \mathrm{cm}^{2}$ of their respective gels. Subjects grouping and treatments are shown in Figure 1.

\section{UV irradiation}

The VC group and Group 1-3 were irradiated with UVB light three times a week (on Monday, Wednesday, and Friday), starting from $50 \mathrm{~mJ} / \mathrm{cm}^{2}$ in the first week, 70 $\mathrm{mJ} / \mathrm{cm}^{2}$ in the second week, and $80 \mathrm{~mJ} / \mathrm{cm}^{2}$ for the last two weeks, resulting in a sum of $840 \mathrm{~mJ} / \mathrm{cm}^{2}$ of UVB received in four weeks. The gels were applied on the mice's skin twice a day: 20 minutes before UV irradiation to allow absorption of gel, and 4 hours 
after irradiation (ROS formation starts 4 hours after UV exposure). Gels were also applied on days when no irradiation was performed. To avoid the acute affects of irradiation, 48 hours after the last irradiation all mice are decapitated, and a sample of their back skin was taken.

\section{Histological examination}

The tissue sample was submerged in $10 \%$ phosphate buffered formalin for 24 hours. To dehydrate the tissue, it was doused in different concentrations of alcohol from $70 \%, 80 \%, 90 \%, 96 \%$, ethanol I, and ethanol II, each for two hours. Then, the tissue was inserted in clearing agents (toluene I and toluene II) for two hours each. In the embedding phase, the tissue went through the infiltration process twice with liquid paraffin $\left(56-58^{\circ} \mathrm{C}\right)$ and planted in liquid paraffin to set for 24 hours. The tissue was sliced into $6 \mu$-thick sections using a microtome. The 5th, 10th, and 15 th slices were stained with Sirius red and for immunohistochemistry.

\section{Evaluation of collagen}

Collagen expression was measured through digital analysis. Photographs of the tissue slides were taken using an LC Evolution camera and Olympus Bx51 microscope with $40 x$ objective magnification. Then, Adobe Photoshop was used to measure the pixel area of collagen (stained bright red), which was divided by the pixel area of the entire slide..$^{8,9}$

\section{Evaluation of matrix metallopro- teinases-1 levels and expression}

ELISA analysis was performed to determine the level of MMP-1 using the Rat Matrix Metalloproteinase-1 Kit produced by MyBiosource, USA. MMP-1 expression was determined through the expression of MMP-1 by dermal fibroblasts, examined through immunohistochemistry staining. The number of fibroblasts was measured

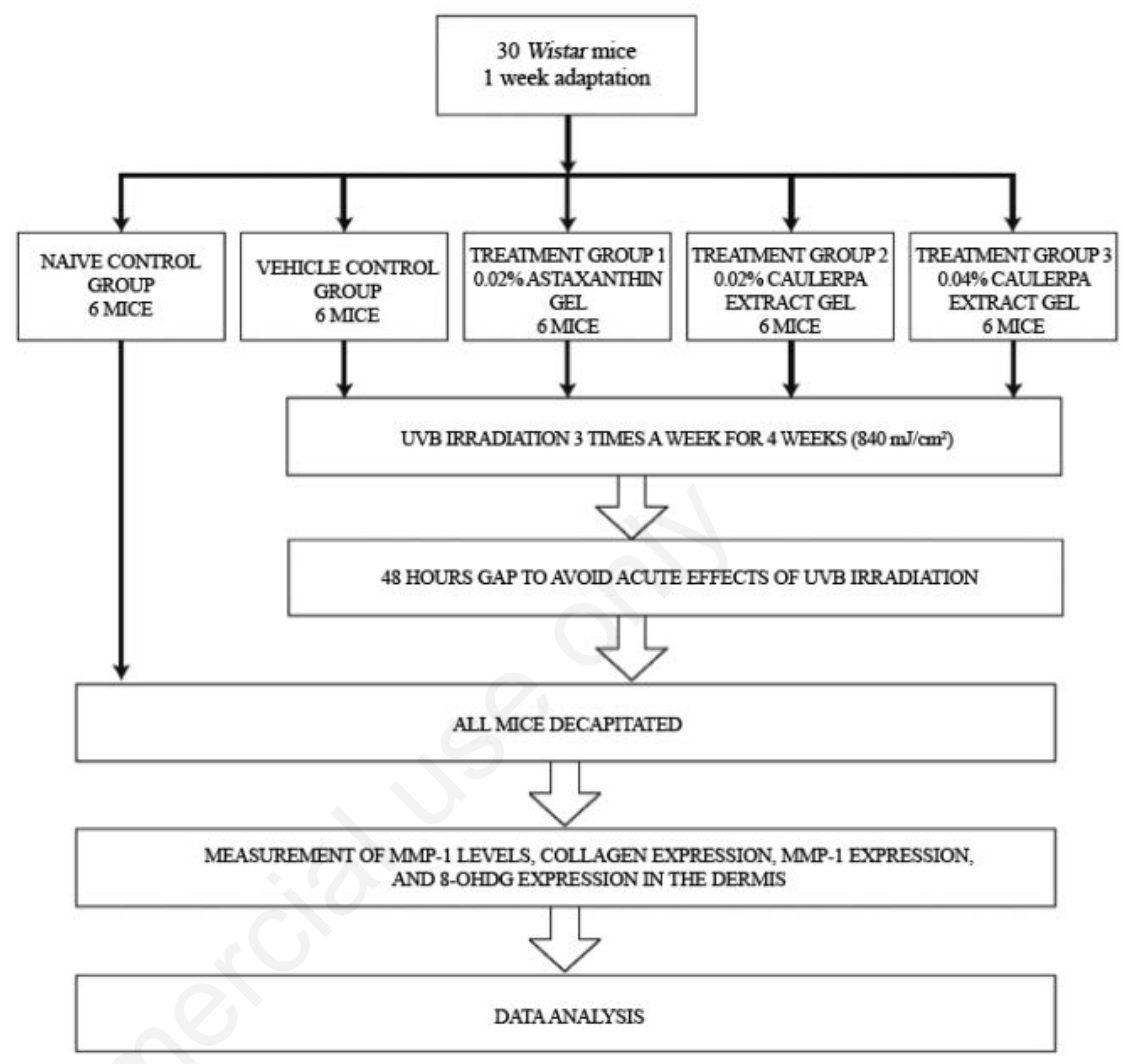

Figure 1. Flowchart of subjects treatment.



Figure 2. Profile of matrix metalloproteinase (MMP)-1 levels in Wistar mice dermal tissue. The naive control group did not receive any treatment; the vehicle control received UV irradiation and gel with no active ingredients; Group 2 received UV radiation and $0.02 \%$ astaxanthin gel; Group 3 received UV radiation and $0.2 \%$ Caulerpa $s p$. extract gel; Group 4 received $U V$ radiation and $0.4 \%$ Caulerpa $s p$. extract gel. Application of topical antioxidants significantly decreases MMP-1 levels. ${ }^{*} \mathrm{P}<0.05$ compared to other treatment groups. †received UVB radiation.

Figure 3. Profile of MMP-1 expression in Wistar mice dermal tissue. The naive control group did not receive any treatment; the vehicle control received UV irradiation and gel with no active ingredients; Group 2 received UV radiation and $0.02 \%$ astaxanthin gel; Group 3 received UV radiation and $0.2 \%$ Caulerpa sp. extract gel; Group 4 received UV radiation and $0.4 \%$ Caulerpa sp. extract gel. Application of topical antioxidants significantly decreases MMP-1 expression. ${ }^{*} \mathbf{P}<0.05$ compared to other treatment groups. †received UVB radiation. 
through 40x magnification on the Olympus Bx51 microscope. MMP-1 expression (\%) was calculated as the number of fibroblasts expressing MMP-1 divided by the total amount of fibroblasts in 5 fields of view.

\section{Evaluation of 8-OHdG}

Expression of 8-OHdG was determined through its expression by dermal fibroblasts, examined through immunohistochemistry staining. The number of fibroblasts was measured through 40x magnification on the Olympus Bx51 microscope. 8-OHdG expression (\%) was calculated as the number of fibroblasts expressing $8-\mathrm{OHdG}$ divided by the total amount of fibroblasts in 5 fields of view.

\section{Statistical analysis}

Data analysis was performed using SPSS (version 20.0). Comparison analyses were performed using one-way analysis of variance, followed by post-hoc tests to determine differences between groups.

\section{Results}

\section{Effect of Caulerpa sp. extract on MMP-1 levels and expression}

MMP-1 plays an important role in collagen degradation due to UVB irradiation. The profile of MMP-1 levels in our subjects is shown in Figure 2; MMP-1 levels in the $\mathrm{VC}$ group is significantly higher than the $\mathrm{NC}$ group which did not receive UV radiation and the treatment groups. When given topical antioxidants in the form of astaxanthin gel and Caulerpa sp. extract gel, MMP1 levels decreased significantly, although no differences were found between the three treatment groups.

MMP-1 expression was measured through immunohistochemistry staining, and the profile can be found in Figure 3. The VC group had the highest amount of MMP-1 expression, significantly higher than the NC group and Group 1-3. Histological examination of the stained slides is shown in Figure 4. Fibroblasts expressing MMP-1 are stained brown, the largest number of which is seen in the $\mathrm{VC}$ group.

\section{Effect of Caulerpa sp. extract on 8- ODhG expression}

Expression of 8-OHdG indicates oxidative DNA damage. Our results show UV irradiation on mice who received no topical antioxidant (VC group) caused a significant increase in 8-OHdG expression, and application of topical antioxidants substantially inhibit $8-\mathrm{OHdG}$ expression; there was no difference between the inhibition properties of astaxanthin gel and Caulerpa sp. extract gel (Figure 5). Figure 6 shows immunohistochemistry staining, where in the $\mathrm{VC}$ group considerable fibroblast damage is seen.

\section{Effect of Caulerpa sp. extract on col- lagen expression}

Degradation of collagen fibers is one of the hallmarks of photoaging in the skin, and Sirius red-stained slides are able to clearly show the structure of collagen fibers. Profile of collagen expression in the subjects is shown in Figure 7. After being irradiated with UV-B, the VC group, which received no active ingredients, had the least amount of collagen expression (Figure 7), significantly lower than Group 1-3, and significant collagen fibers degradation (Figure 8). The groups who received treatment with astaxanthin and Caulerpa sp. extract as antioxidant showed higher collagen expression (Figure 7) and well-preserved structure of collagen fibers (Figure 8).

\section{Discussion and Conclusions}

UV exposure to the skin triggers processes of external aging called photoaging, which includes decreasing epidermal thickness, cellular dysplasia, infiltration of inflammatory cells, and increasing elastin and collagen degradation. ${ }^{10}$ Fibroblasts in the dermis are the main producers of collagen fibers, elastin, and supporting tissue in the ECM; they also secrete MMP enzyme, whose role is protein degradation. ${ }^{11,12}$ Internal aging causes an increase in MMP-1 and MMP-9, which leads to a decrease in the synthesis of collagen and other ECM proteins. ${ }^{13}$ The presence of UV irradiation further enhances this process, increasing MMP activity and protein degradation. Several studies reported that MMP-1 is the main enzyme responsible for collagen degradation in human skin and it is induced by UV irradiation, especially UVB. ${ }^{14-16} \mathrm{UV}$ irradiation induces the formation of ROS, which contributes to oxidative damage of

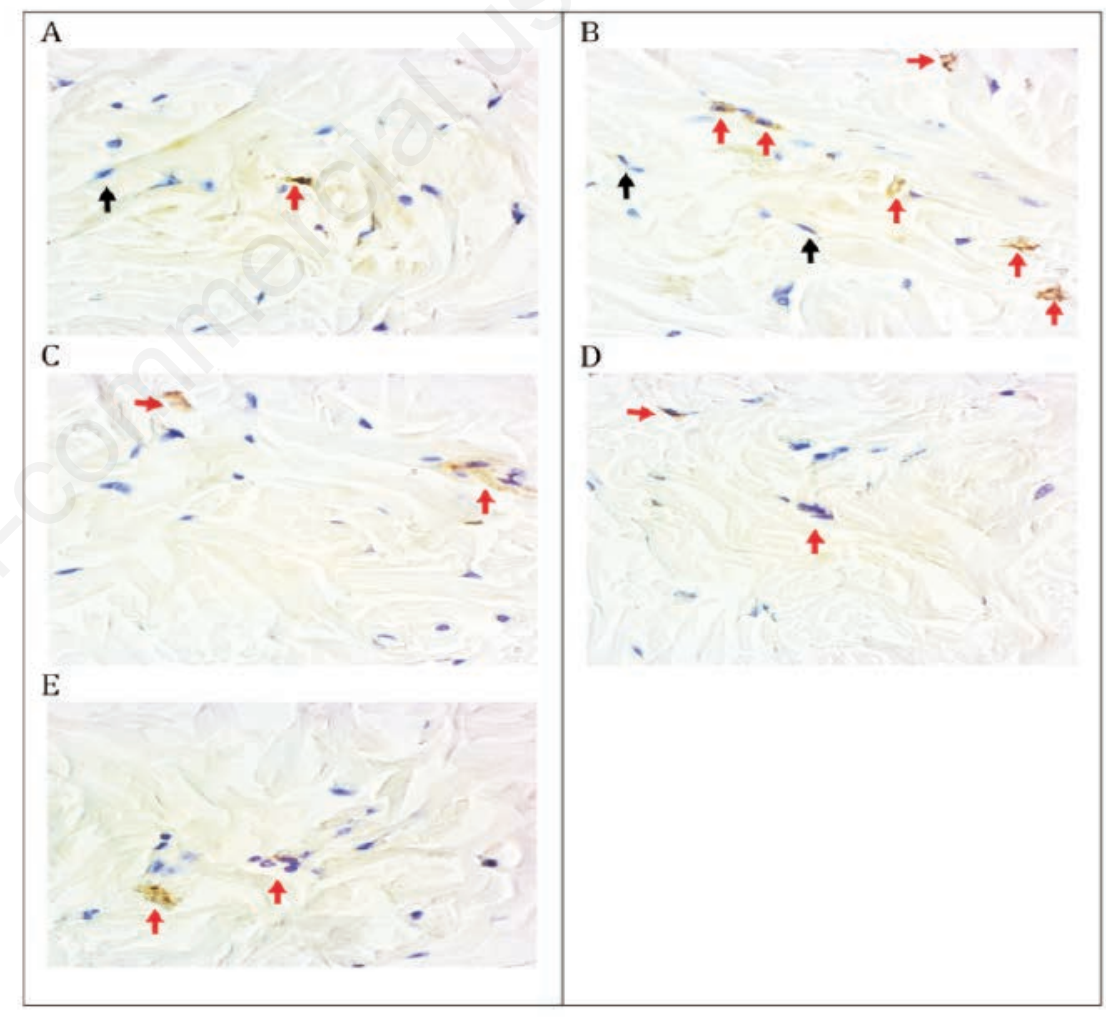

Figure 4. Immunohistochemistry staining showing MMP-1 expression in Wistar mice dermal tissue, 40x magnification. A: naive control group, showing non-MMP-1 expressing fibroblasts (red arrowhead) and MMP-1-expressing fibroblasts (black arrowhead) whose cytoplasm is stained brown with fragmented nucleus; B: vehicle control (VC) group, red arrowheads show more fibroblasts were expressing MMP-1 compared to fibroblasts that were not expressing MMP-1 (black arrowheads); C: Group 1, the number of fibroblasts expressing MMP-1 (red arrowheads) was fewer than in the VC group; D: Group 2, the number of fibroblasts expressing MMP-1 (red arrowheads) was fewer than in the VC group; E: Group 3, the number of fibroblasts expressing MMP-1 (red arrowheads) was fewer than in the VC group. 
the DNA. 8-OHdG is the marker for oxidative DNA damage; it is a product of $\mathrm{C} 8$ oxidation in guanine, the main target of ROSinduced oxidative damage in the DNA. ${ }^{17}$

Sunscreens are the standard topical agent used to avoid photoaging from UV irradiation. A study by Haywood reported sunscreens only reduce free radical formation in the skin by $55 \%$, thus addition of topical antioxidants is expected to improve photoaging prevention. ${ }^{6}$

Caulerpa $s p$. is a type of seaweed widely available in the Indo-Pacific region, traditionally consumed as food. Studies have shown various antioxidant agents are present in Caulerpa $s p$, including vitamin A, vitamin $\mathrm{C}$, vitamin $\mathrm{E}$, astaxanthin, and polyphenols. ${ }^{18}$ We investigated Caulerpa $s p$. extract's potential protective properties against photoaging, and our results show this compound significantly reduces effects of photoaging. No side effects were observed during treatment of subjects with

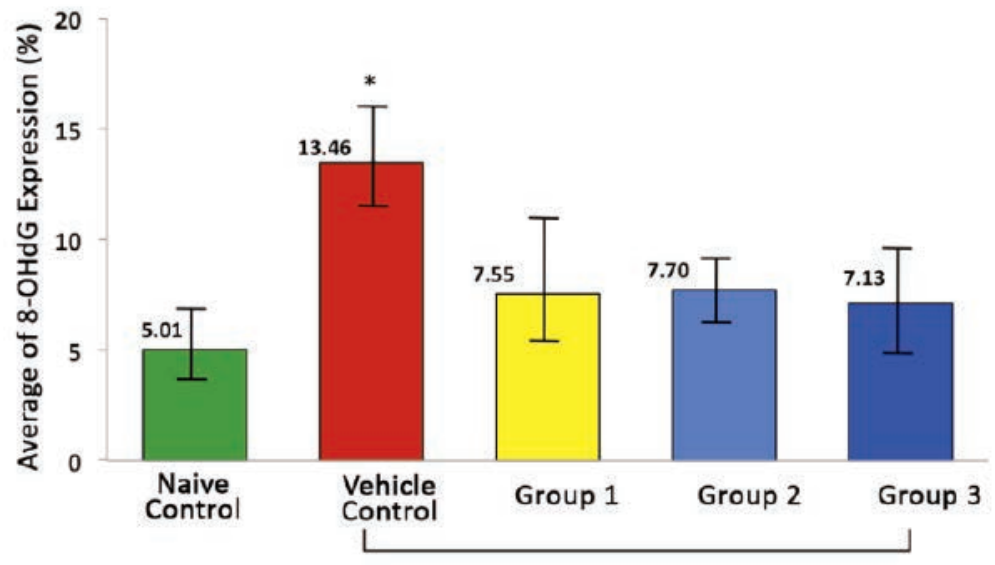

UVB Irradiation

Figure 5. Profile of 8-OHdG expression in Wistar mice dermal tissue. The naive control group did not receive any treatment; the vehicle control (VC) received UV irradiation and gel with no active ingredients; Group 2 received UV radiation and $0.02 \%$ astaxanthin gel; Group 3 received UV radiation and $0.2 \%$ Caulerpa $s p$. extract gel; Group 4 received UV radiation and $0.4 \%$ Caulerpa $s p$. extract gel. Application of topical antioxidants significantly decreases 8 -OHdG expression. ${ }^{*} \mathrm{P}<0.05$ compared to other treatment groups. †received UVB radiation.
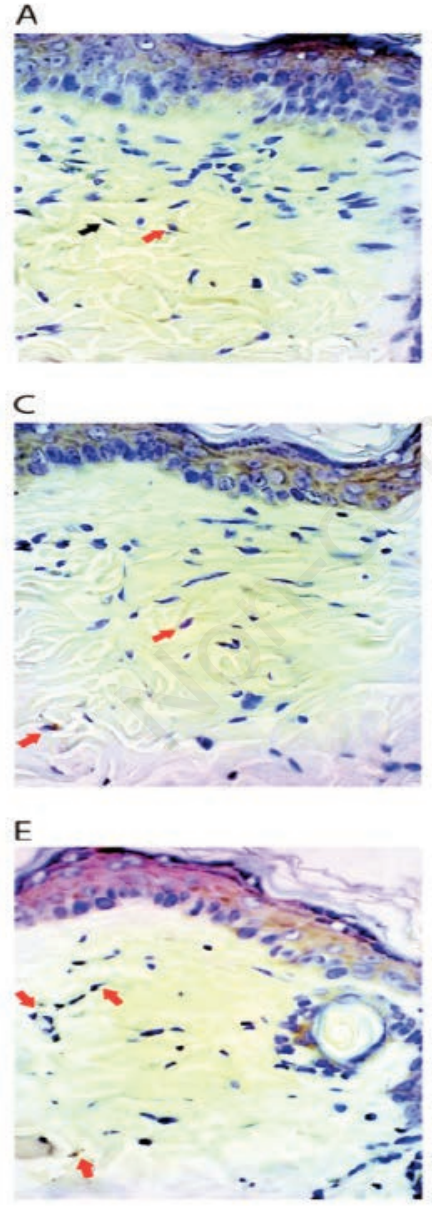

B
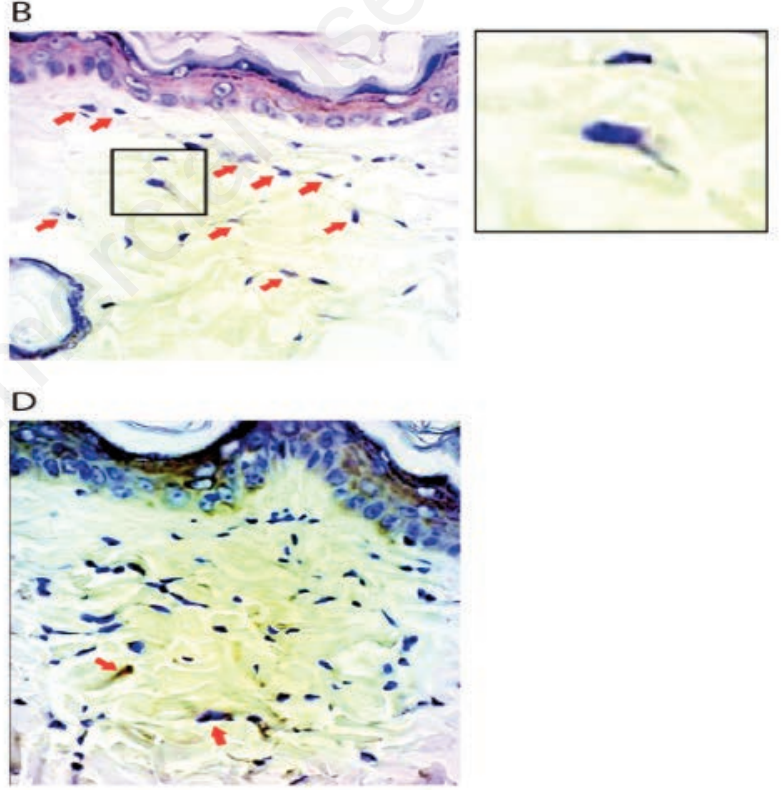

Figure 6. Immunohistochemistry staining showing 8-OHdG expression in Wistar mice dermal tissue, 40x magnification. A: naive control group, showing non-8-OHdG expressing fibroblasts (black arrowhead) and 8-OHdG-expressing fibroblasts (red arrowhead); B: vehicle control (VC) group, red arrowheads show damaged fibroblasts and an increase in 8-OHdG expression; C: Group 1, the number of damaged fibroblasts (red arrowheads) was fewer than in the VC group, with a decrease in 8-OHdG expression; D: Group 2, the number of damaged fibroblasts (red arrowheads) was fewer than in the VC group, with a decrease in 8-OHdG expression; E: Group 3, the number of damaged fibroblasts (red arrowheads) was fewer than in the VC group, with a decrease in 8-OHdG expression. 
topical Caulerpa sp. extract and astaxanthin gel.

MMP-1 levels and expression in mice who received topical Caulerpa $s p$. extract are significantly lower than mice in the VC group, and this decrease does not differ significantly from the decrease caused by astaxanthin gel, a known antioxidant. Our results show the difference in Caulerpa sp. extract concentrations did not cause significantly different antioxidant properties, which mean the properties are not dosedependent. This decrease in MMP-1 corresponds to the decrease in collagen degradation in groups receiving treatment, due to the inhibition of the enzymes responsible for collagen degradation. Furthermore, we found Caulerpa sp. extract inhibits oxidative DNA damage, indicated by the low amount of 8-OHdG expression in treatment groups compared to the VC group.

The antioxidant properties of Caulerpa $s p$. extract are due to the various antioxidant

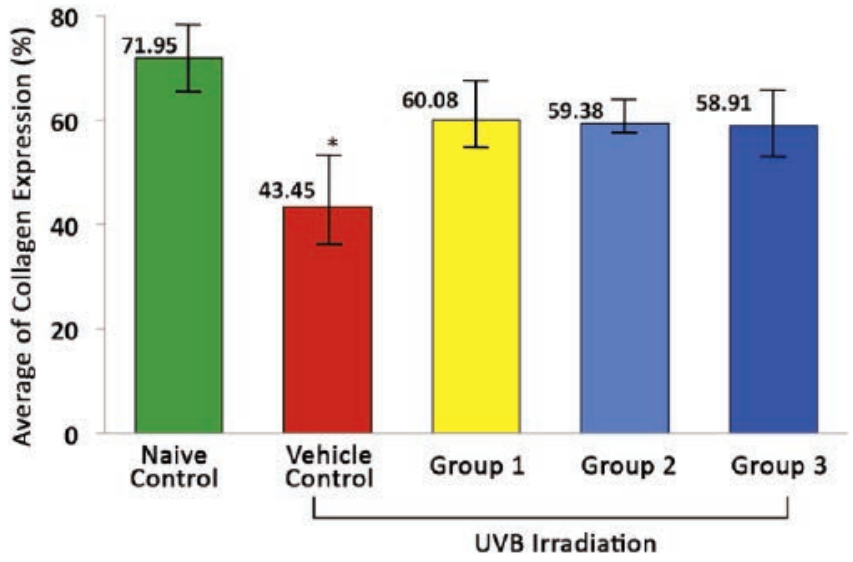

Figure 7. Profile of collagen expression in Wistar mice dermal tissueThe naive control group did not receive any treatment; the vehicle control received UV irradiation and gel with no active ingredients; Group 2 received UV radiation and $0.02 \%$ astaxanthin gel; Group 3 received UV radiation and $0.2 \%$ Caulerpa sp. extract gel; Group 4 received UV radiation and $0.4 \%$ Caulerpa sp. extract gel. Application of topical antioxidants significantly increases collagen expression. ${ }^{*} \mathbf{P}<0.05$ compared to other treatment groups. †received UVB radiation.

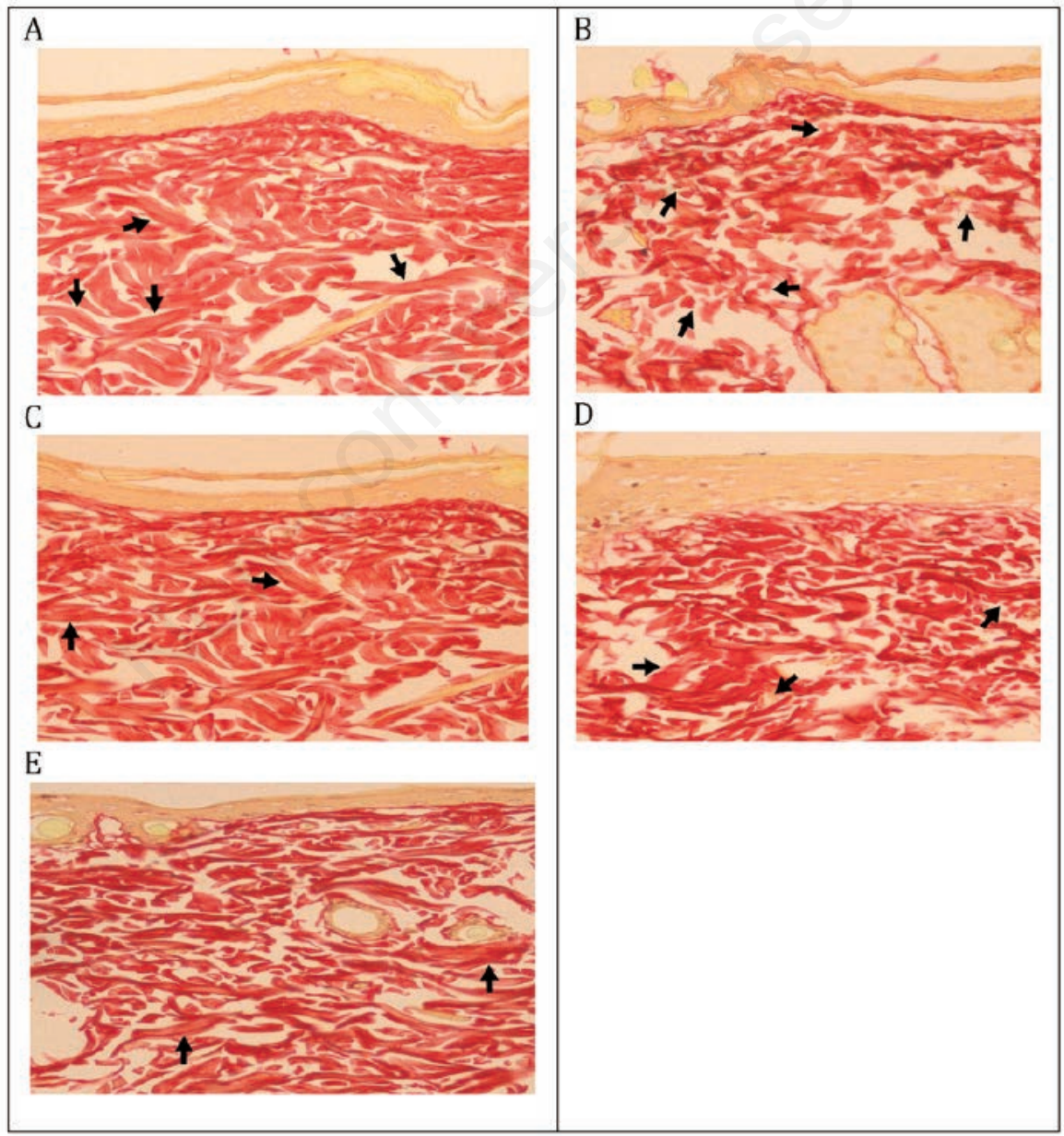

Figure 8. Sirius red staining of collagen expression in Wistar mice dermal tissue, 40x magnification. A: naive control group, showing wellorganized and dense collagen fibers (arrowheads: intact collagen fibers); B: vehicle control group, damage was present on the collagen fibers' structure and organization (arrowheads: fragmented collagen fibers); C: Group 1, collagen fibers are well-organized (arrowheads: intact collagen fibers); D: Group 2, collagen fibers are well-organized (arrowheads: intact collagen fibers); E: Group 3, collagen fibers are well-organized (arrowheads: intact collagen fibers). 
agents contained in the plant, such as vitamin A, C, E, and polyphenols. Vitamin A in the form of carotenoids is known to inhibit MMP-1, preventing collagen degradation. ${ }^{19}$ Vitamin C decreases ROS activities and plays a role in collagen biosynthesis, while vitamin E prevents lipid peroxidation, guarding the structure of cell membrane. Polyphenols in seaweed are reported as potent inhibitors of NF-kB and AP-1 activities, which lead to nhibition of MMP-1 expression. ${ }^{20}$ Our results are corroborated by Hantke et al.'s study, which found a compound containing a combination of vitamin $\mathrm{C}, \mathrm{E}$, and polyphenols decrease MMP-1 expression by $40 \% .{ }^{21}$ Our results show no difference between the effects of topical $0.2 \%$ and $0.4 \%$ Caulerpa $s p$. extract and topical $0.2 \%$ astaxanthin. Astaxanthin is a known naturally-occurring carotenoid with potent antioxidant properties, which is reported to be 550 times more potent than vitamin $\mathrm{E}$ and 40 times more potent than beta carotene in scavenging oxygen singlets. ${ }^{22}$ Arakane's study found adding astaxanthin to sunscreen formulas was beneficial in increasing UV protection. The non-significant difference between the effects of Caulerpa sp. extract and astaxanthin in our study indicates Caulerpa sp. extract has similar antioxidant potency to astaxanthin, and has the potential to be a beneficial addition to photoaging protection, due to its rich and varying antioxidant compounds. Whether or not similar effects can be observed on the human skin remains a subject for future investigation.

In conclusion, our study presents Caulerpa $s p$. extract as a potential antioxidant agent for the prevention of photo-aging through its inhibitory activity of MMP-1 and prevention of oxidative DNA damage.

\section{References}

1. Ichihashi M, Ando H, Yoshida M, et al. Photoaging of the skin. J Anti-Aging Med 2009;6:46-59.

2. Cavinato M, Jansen-Durr P. Molecular mechanisms of UVB-induced senescence of dermal fibroblasts and its relevance for photoaging of the human skin. Exp Gerontol 2017;94:78-82.

3. Hwang E, Lee DG, Park SH, et al. Coriander leaf extract exerts antioxidant activity and protects against UVBinduced photoaging of skin by regulation of procollagen type $\mathrm{I}$ and MMP-1 expression. J Med Food 2014;17:985-95.

4. Valavanidis A, Vlachogianni T, Fiotakis C. 8-hydroxy-2'-deoxyguanosine (8OhdG): a critical biomarker of oxidative stress and carcinogenesis. J Environm Sci and Health 2009;27:12039.

5. Helfrich YR, Sachs DL, Voorhees JJ. Overview of skin aging and photoaging. Dermatol Nurs 2008;20:177-83.

6. Haywood R, Wardman P, Sanders R, Linge C. Sunscreens inadequately protect against ultraviolet-A-induced free radicals in skin: implications for skin aging and melanoma? J Invest Dermatol 2003;121:862-8.

7. Wiraguna

AAGP.

Photochemoprotection effect of active component of bulung boni (Caulerpa spp.) on rats' skin. Int J Biomed Sci 2013 [in press].

8. Lehr HA, van der Loos CM, Teeling P, Gown AM. Complete chromogen separation and analysis in double immunohistochemical stains using Photoshop-based image analysis. J Histochem Cytochem 1999;47:119-26.

9. Widodo Y, Dahlan I. The effect of narrow and broad band ultraviolet $B$ onto keloid fibroblast-VEGF expressions. Berkala Ilmu Kedokteran 2007;39:82-7.

10. Hong H, Jung M, Choe SJ, et al. The effect of Rhus verniciflua stokes extracts on photo-aged mouse skin. Ann Dermatol 2017;29:295-301.

11. Chu DH. Development and Structure of The Skin. In: Wolff K, Goldsmith LA, Katz SL, Gilchrest BA, Paller AS, Leffell DJ, eds. Fitzpatrick's Dermatology in General Medicine. 7th ed. New York: McGrawHill; 2008. pp 57-72.

12. Jouni U, Mon-li C, Richard G, Arthur ZE. Collagen, Elastic Fibers, and Extracellular Matrix of The Dermis. In: Wolff K, Goldsmith LA, Katz SL, Gilchrest BA, Paller AS, Leffell DJ, eds. Fitzpatrick's Dermatology in General Medicine. 7th ed. New York: McGrawHill; 2008. pp 517-542.

13. Varani J, Dame MK, Rittie L, et al.
Decreased collagen production in chronologically aged skin: roles of agedependent alteration in fibroblast function and defective mechanical stimulation. Am J Pathol 2006;168:1861-8.

14. Quan T, Qin Z, Xia W, et al. Matrixdegrading metalloproteinases in photoaging. J Investig Dermatol Symp Proc 2009; 14:20-4.

15. Yulianto, I. The changes of fibroblast cells due to UVB irradiation in various doses: an in vitro experiment [dissertation]. Surabaya: Universitas Airlangga; 2006.

16. Lee YR, Noh EM, Jeong EY, et al. Cordycepin inhibits UVB-induced matrix metalloproteinase expression by suppressing the NF- $\kappa \mathrm{B}$ pathway in human dermal fibroblasts. Exp Mol Med 2009;41:548-54.

17. Bruskov VI, Malakhova LV, Masalimov ZK, Chernikov AV. Heat-induced formation of reactive oxygen species and 8-oxoguanine, a biomarker of damage to DNA. Nucleic Acids Res 2002;30:1354-63.

18. Julyasih KSM. Ekstrak Bulung Boni (Caulerpa spp.) dan Bulung Sangu (Gracilaria spp) Memperbaiki Profil Lipid, Menurunkan Kadar Malonaldehid, dan Enzim HMG-KoA Reduktase Tikus Wistar Diberikan Diet Tinggi Kolesterol [dissertation in Indonesian]. Denpasar: Universitas Udayana; 2011.

19. Chen L, Hu JY, Wang SQ. The role of antioxidants in photoprotection: a critical review. J Am Acad Dermatol 2012;67:1013-24.

20. Joe MJ, Kim SN, Choi HY, et al. The inhibitory effects of eckol and dieckol from Ecklonia stolonifera on the expression of matrix metalloproteinase1 in human dermal fibroblasts. Biol Pharm Bull 2006;29:1735-9.

21. Hantke B, Lahmann C, Venzke K, et al. Influence of flavonoids and vitamins on the MMP- and TIMP-expression of human dermal fibroblasts after UVA irradiation. Photochem Photobiol Sci 2002;1:826-33.

22. Naguib YM. Antioxidant activities of astaxanthin and related carotenoids. J Agric Food Chem 2000;48:1150-4. 